\title{
THE DISTRIBUTION OF BATS IN THE NETHERLANDS
}

\author{
by
}

\author{
S. BRAAKSMA \\ State Forest Service, Department of Nature Conservation, Utrecht, The Netherlands
}

The Research Institute for Nature Management (R.I.N.) has compiled all available information on the distribution of bats in the Netherlands up till 1968. The data were derived from literature and museum specimens, as well as from numerous unpublished observations.

Around 1960 much was known already on the winter dwellings of various species of bats, especially those in marl pits and fortresses. Less details were available concerning the distribution of bats in summer. Only one species, Nyctalus noctula, had been studied during the summer. During the past ten years valuable information on hibernacula could be added by continued research in marl pits and fortresses, and by investigations in cellars of castles and in former ice cellars. Besides, Dutch investigators started to pay attention to summer resorts of bats in towers and on lofts of churches, castles and other old buildings. From 1961 to 1969 about 1320 buildings have been inspected.

The distribution maps constructed from these data will be published elsewhere. They show the following overall characteristics:

Rhinolophus ferrumequinum occurs in the Netherlands in the marl pits in the south of the province of Limburg only. At present it is a rare winter guest, whose numbers have been decreasing rapidly, partly through the use of toxic chemicals by mushroom growers. The last nursing colony of Greater Horseshoe Bats, situated in the "Pietersberg" near Maastricht disappeared years ago when this marl excavation was largely exploited by a cement factory.

The Lesser Horseshoe Bat, Rhinolophus hipposideros, is mainly restricted to the same area. It is less rare in the marl pits than $R$. ferrumequinum, but its numbers are rapidly decreasing too. In former years Lesser Horseshoes have been found more or less regularly in summer on the lofts of three buildings in this part of the country. In these places small nursing colonies have existed up till at least 1960. Incidentally, Lesser Horseshoe Bats have been observed as far North as the provinces of Utrecht and Zuid-Holland during the summer.

Myotis mystacinus is presently one of the most frequent species in marl pits, fortresses, cellars, and ice cellars in the central and southern parts of the country. Yet, so far only two nursing colonies are known to have existed: one behind a shutter of a castle in the province of Utrecht, and one on a church loft in South-Limburg. Both colonies were abandoned, probably as a result of human disturbance. Small nursing colonies are supposed to exist in two churches recently investigated.

Myotis nattereri occurs primarily in the central and southern parts of the Netherlands. It is rare in winter and is hardly at all seen in summer.

Myotis emarginatus is, as might be expected for a southern species, restricted to the province of Limburg as well.

Myotis bechsteini was found, since its first discovery in a marl pit in 1938, now and then in several of such hibernation quarters in South Limburg.

Myotis daubentonii has been observed in several parts of the country, especially during the winter. So far, only one certain and two presumed nursing colonies of this species have been known. One of these was in a hollow tree in the province of Utrecht, the other two in churches in Friesland. In 1969 only one of these colonies was still there. about 120 bats were found in the church tower.

Of Myotis dasycneme the only nursing colonies known in western Europe are in the Netherlands. In summer this bat occurs almost exclusively in the provinces of Friesland and Noord-Holland. Of 12 nursing colonies discovered in this area at least six existed still in 1969. Our most important dis- 
covery last year was that of a number of 300 to 350 Pond Bats on a church loft in Friesland. Winter dwellings of this species in the country are mainly located in the South Limburg marl pits.

Myotis myotis occurs primarily in the southern and central parts of the country. Six nursing colonies of this species - two of which doubtful have been discovered. One of these was situated in a marl pit. The others were on the lofts of old churches, all covered with slated roofs. Only one of these colonies, moreover a small one, is still existing. In winter Myotis myotis can be observed in the marl pits as well as in ice cellars, but their numbers are steadily decreasing. In 1969 no Mouse-eared Bats were found in the cellars of three castles and some fortresses where these bats had regularly been observed in previous years.

Pipistrellus nathusii seems to be one of the rarest species in the Netherlands. It has been found in nine localities only. It is very likely, however, that the species occurs more frequently since pipistrelles use to hid in inaccessible places and, except in hand, Pipistrellus nathusii can not be distinguished from the next species.

Pipistrellus pipistrellus is certainly a common bat in many parts of the country. However, precise information is comparatively scarce. In many cases the investigators were able only to report the presence of small bats, "evidently Pipistrellus species". In summer pipistrelles are regularly found in hollow trees and in bird or bat boxes. Presumably, nursing colonies are in such places too. Actually, we never saw these however. Summer colonies discovered in buildings were nearly always in inaccessible places between roof boards or in wall fissures. In 1969 a colony of 74 specimens was discovered on a church loft in the province of Zeeland. In winter, Pipistrellus pipistrellus is rarely seen in marl pits, fortresses and ice cellars. Many of these bats seem to hibernate in clusters in wall crevices of old buildings. In the winter of $1968 / 69$ a colony of some 50 animals was found during repairs on the walls of the old royal castle "Het Loo" (prov. Gelderland).

Eptesicus serotinus is another common species. Summer resorts of the Serotines are usually easier to find than those of the pipistrelles, at least during the nursing period. At this time of the year the females seem to prefer the open parts of the lofts of buildings, but as soon as the young bats are able to fly both females and juvenils tend to hide in far less accessible places, where they may stay until the next nursing season. Twenty-two nursing colonies - of which 10 uncertain - have been discovered so far.

Nyctalus noctula is found in several parts of the country where a suitable habitat is available. Its occurrence is mainly restricted to old woods with hollow oaks and beeches. The Noctules live in such trees both in summer and winter. Nine nursing colonies have been known. In two of these over 150 bats were living together in one tree. Several colonies got lost by tree cutting. Artificial hides have been offered to compensate for the loss of hollow trees. However, only small numbers of Noctules were reported from special bat boxes and from bird nesting boxes so far. As a tree bat, the noctule has been found in Holland only twice in buildings, once in summer and once in winter. The winter colony was in the royal castle "Het Loo" again, well hidden in a hole between the walls.

Plecotus auritus is one of the most common bats in the Netherlands. Several nursing colonies were discovered in the buildings investigated. At present we know about 350 summer resorts of Longeared Bats. Among these there are at least 30 places where nursing colonies exist. Most of the latter are located in the southern part of the country. In the northern provinces especially, Plecotus has a preference for buildings with slate-covered roofs. Apart from buildings, Long-eared Bats have been observed in hollow trees and in various bird and bat boxes. Three small nursing colonies have been found in such boxes. Winter observations of Plecotus auritus are less numerous. Longeared Bats are usually observed in small numbers in fortresses and ice cellars. In the marl pits they are remarkably rare. There are indications that Plecotus auritus may stay in one building throughout the year: in the autumn they leave the church lofts and sometimes hide in fissures lower in the tower or sometimes in the cellars or even in old graves.

Plecotus austriacus was discovered in the Netherlands in 1960 in a South Limburg marl pit. Since then, the species has been found in at least eleven other places. These are all in the southern part of the country. It is supposed, however, that the species is extending its range northward. In winter, $P$. austriacus has been found in marl pits only. All summer resorts reported were located on slate covered church lofts.

Barbastella barbastellus has always been a rare winter visitor in the Limburg marl pits, and its numbers seem to have decreased even more in recent years. 
Summarizing, we see that in the Netherlands nursing colonies have been found in 10 or 11 out of 16 bat species. Only five species are known to be common during the summer. The bat population as a whole has no doubt been rapidly decreas- ing since the beginning of the century. It is even likely that at least four species seem to be in danger of complete extinction in the country: Barbastella barbastellus, Rhinolophus ferrumequinum, Myotis myotis, and Rhinolophus hipposideros. 